\title{
An analytical study on the performance characteristics of a multi-stage thermoelectric cooling system
}

\author{
D. $\mathrm{Kim}^{1}, \mathrm{C} . \mathrm{Lim}^{1} \& \mathrm{Y} . \mathrm{Kim}^{2}$ \\ ${ }^{1}$ Graduate School of Mechanical Engineering, Korea University, Korea \\ ${ }^{2}$ School of Mechanical Engineering, Korea University, Korea
}

\begin{abstract}
A thermoelectric module is a device, which can transfer heat from one surface to another surface when a current is applied. A cooling system employing the thermoelectric module is generally known as a thermoelectric cooling system. A thermoelectric cooling system has no moving parts and does not require any refrigerant, so they are environmentally friendly, inherently reliable, and virtually maintenance free. In this study, a numerical analysis for optimization of a thermoelectric cooler is presented. A single-stage system, cuboids type twostage system and pyramid type two-stage system are analyzed concerning maximum cooling capacity. For two-stage thermoelectric systems, which are composed of two thermoelectric modules, the optimum ratio of current for each stage is analyzed theoretically. The cooling load and heat sink design are also analyzed to optimize the cooling capacity. When the temperature of the hot side of the thermoelectric module was fixed for all systems, the pyramid type twostage system showed an approximately $10.48 \%$ higher cooling capacity than that of a single system. The method to improve the performance of the pyramid type two-stage system was suggested by reducing the wasted area of the module surface.
\end{abstract}

Keywords: thermoelectric module, multi-stage, refrigerator.

\section{Introduction}

As there are energy depletion issues all over the world, needs of new technologies to replace conventional compression-type refrigerator systems have arisen. One of the alternatives is the thermoelectric cooling system. A 
thermoelectric module is a device, which can transfer heat from one surface to another when a current is applied to the module. The thermoelectric module has several advantages such as accuracy, no noise, a small size, and it is eco-friendly. For these reasons, the thermoelectric module has been widely used in the military industry, the medical field, and in many commercial products [1-4]. In this research, the theoretical design and analysis of a thermoelectric cooler is presented. In addition, a method to optimize a two-stage thermoelectric system is suggested.

\section{Theoretical analysis}

Figure 1 shows the thermoelectric cooler that is designed in this study. The thermoelectric module is attached on the inside wall of a refrigerator. On each side of the thermoelectric module, a heat sink composed of a fin and fan is placed so that it transfers heat from the inside of the refrigerator to the outside effectively. Fig. 2 shows the cases of thermoelectric arrangement considered in this research. Two types of thermoelectric modules with different sizes were used; $40 \times 40 \mathrm{~mm}$ and $50 \times 50 \mathrm{~mm}$.

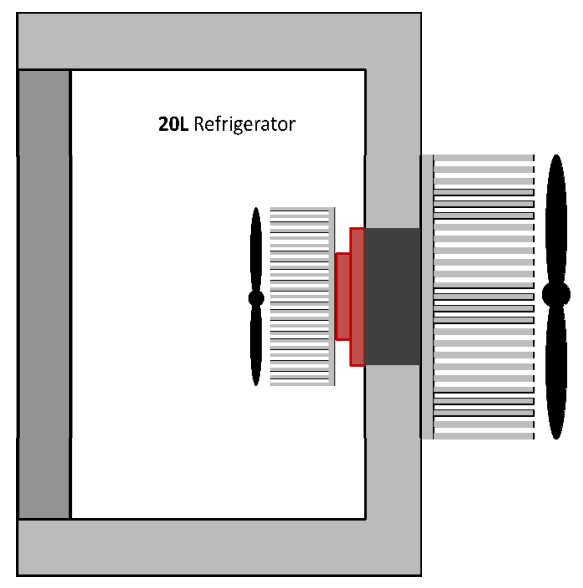

Figure 1: Schematic diagram of the thermoelectric cooler.

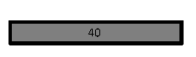

(a)

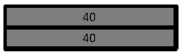

(b)

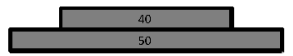

(c)

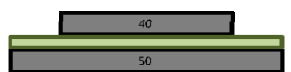

(d)

Figure 2: Arrangement of thermoelectric modules. (a) single-stage, (b) cuboid type two-stage, (c) pyramid type two-stage, (d) pyramid type two-stage with high conductance material. 


\subsection{Component analysis}

Fig. 3 shows the thermal circuit for a thermoelectric cooling system. A basic experiment was conducted to find the thermal resistance of a cooling heat sink $\left(\mathrm{R}_{\mathrm{hs}, \mathrm{c}}\right)$ and the overall heat transfer coefficient (UA) of the refrigerator. For the basic experiment, a commercial $20 \mathrm{~L}$ refrigerator was remodelled to a thermoelectric cooling system. Fig. 4 shows the measured temperatures for each component. Table 1 shows the calculation results based on the measured temperatures.

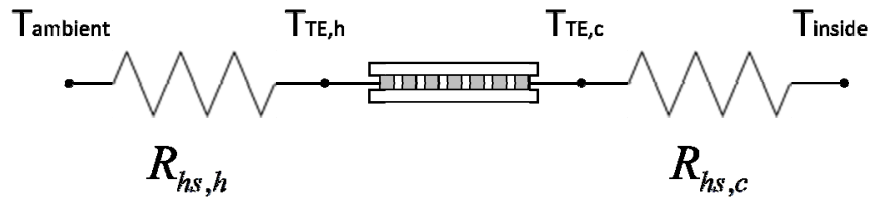

Figure 3: Thermal circuit of the thermoelectric cooling system.

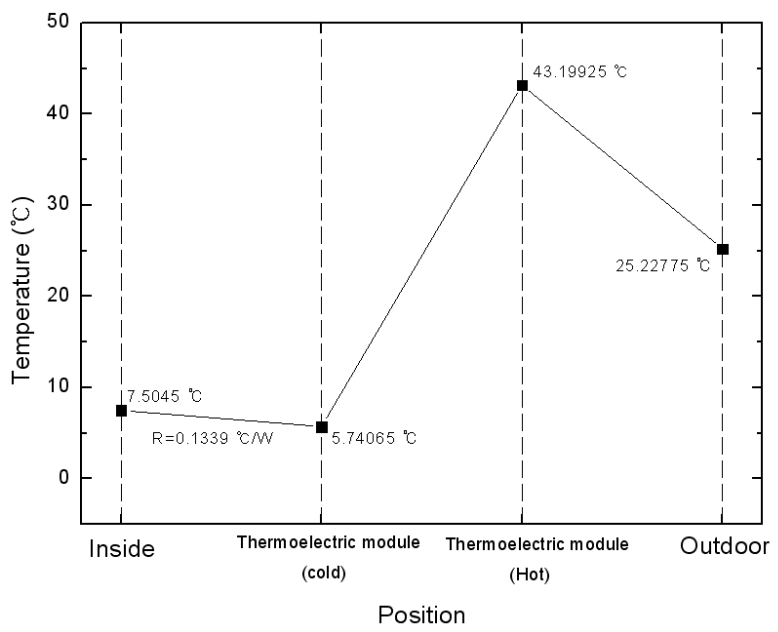

Figure 4: Temperatures of the thermoelectric cooler.

Table 1: Calculation results based on the experiment.

\begin{tabular}{|c|c|}
\hline $\mathrm{Q}_{\mathrm{c}}$ & $28.10 \mathrm{~W}$ \\
\hline $\mathrm{Q}_{\mathrm{h}}$ & $87.05 \mathrm{~W}$ \\
\hline $\begin{array}{c}\text { Heat transfer } \\
\text { coefficient, UA }\end{array}$ & $1.6600 \mathrm{~W} /{ }^{\circ} \mathrm{C}$ \\
\hline $\begin{array}{c}\text { Thermal } \\
\text { resistance, } \mathrm{R}_{\mathrm{hs}, \mathrm{c}}\end{array}$ & $0.1339^{\circ} \mathrm{C} / \mathrm{W}$ \\
\hline
\end{tabular}




\subsection{Analytical study overview}

The flow chart for theoretical simulation analysis is shown in Fig. 5. Visual Basic 6.0 was used to conduct and calculate the flow chart. The calculation starts with assumption of $\mathrm{T}_{\mathrm{c}}$. Then, the cooling load of refrigerator and the cooling capacity of the thermoelectric module can be calculated individually. For steady state, the cooling capacity and cooling road must be the same. Iteration is conducted to satisfy energy balance until the cooling load of the refrigerator and the cooling capacity of the thermoelectric module become the same. In this way, $\mathrm{Q}_{\mathrm{c}}$ can be obtained for specific current input. The change of $\mathrm{Q}_{\mathrm{c}}$ with variable currents can also be calculated by repeating previous steps with different current inputs.

The input data for the analytical program is presented in Table 2. The information of thermoelectric modules was obtained from the manufacturer. Assume that the temperature on the hot side of the thermoelectric module is fixed at $40^{\circ} \mathrm{C}$ and the contact resistances are negligible.

Table 2: Input data for the theoretical simulation program.

\begin{tabular}{|c|c|c|}
\hline Thermoelectric module & HMN 6040 & HMN 1550 \\
\hline Seebeck coefficient, $\alpha\left(\mathrm{VK}^{-1}\right)$ & 0.051816 & 0.045974 \\
\hline Electrical resistance, $\mathrm{R}(\Omega)$ & 1.956 & 0.882 \\
\hline Thermal conductance, $\mathrm{K}\left(\mathrm{WK}^{-1}\right)$ & 0.464 & 0.932 \\
\hline $\mathrm{M}$ (Number of semiconductor) & 254 & 254 \\
\hline Size & $40 \times 40 \mathrm{~mm}$ & $50 \times 50 \mathrm{~mm}$ \\
\hline Ambient temperature & \multicolumn{2}{|c|}{$25^{\circ} \mathrm{C}$} \\
\hline $\mathrm{T}_{\mathrm{h}}$ & \multicolumn{2}{|c|}{$20 \mathrm{~L}$ (fixed) } \\
\hline Internal volume & \multicolumn{2}{|c|}{20} \\
\hline
\end{tabular}

\subsection{System modelling}

$\mathrm{Q}_{\mathrm{c}}$ and $\mathrm{Q}_{\mathrm{h}}$ of the thermoelectric modules are calculated from eqns (1) and (2).

$$
\begin{aligned}
& \mathrm{Q}_{\mathrm{c}}=\alpha \mathrm{IT}_{\mathrm{c}}-\frac{1}{2} \mathrm{I}^{2} \mathrm{R}-\mathrm{K}\left(\mathrm{T}_{\mathrm{h}}-\mathrm{T}_{\mathrm{c}}\right) \\
& \mathrm{Q}_{\mathrm{h}}=\alpha \mathrm{IT}_{\mathrm{h}}+\frac{1}{2} \mathrm{I}^{2} \mathrm{R}-\mathrm{K}\left(\mathrm{T}_{\mathrm{h}}-\mathrm{T}_{\mathrm{c}}\right)
\end{aligned}
$$




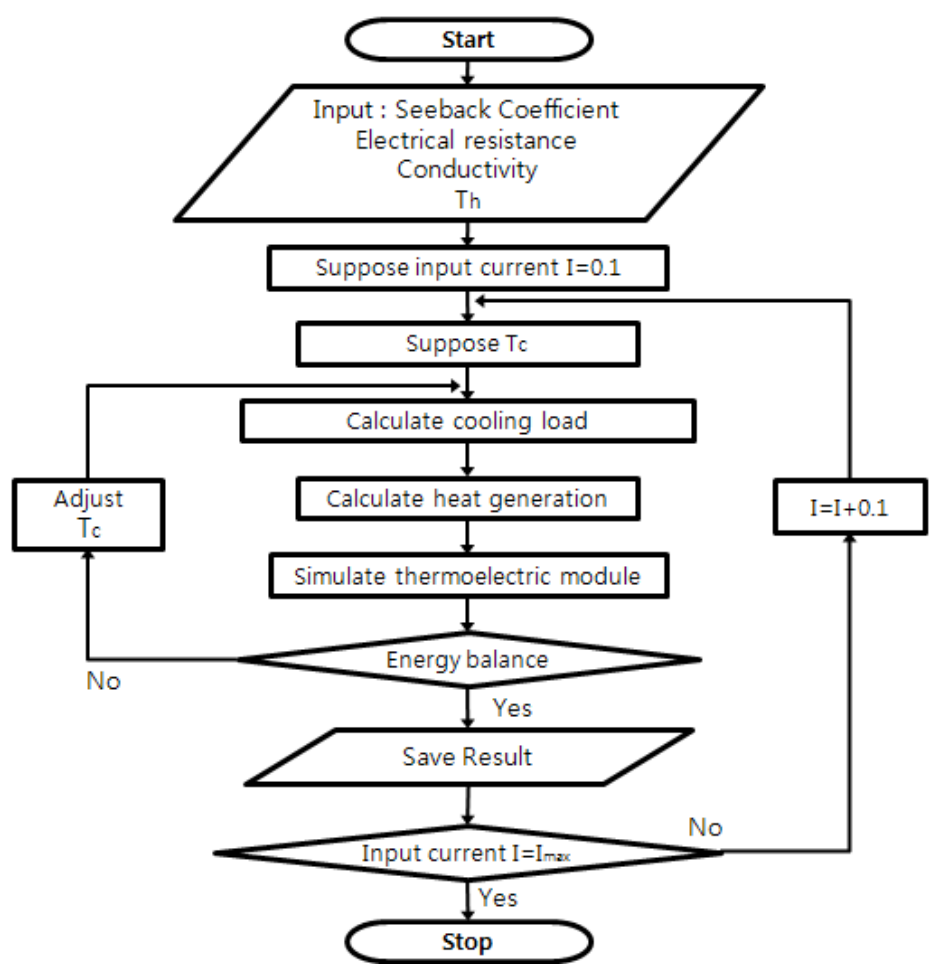

Figure 5: Flow chart of the theoretical simulation program.

Each component of the right side represents heat from peltier effect, heat generation due to the electrical resistance, and heat transfer loss by conduction, respectively.

$$
\begin{gathered}
\mathrm{T}_{\mathrm{i}}=\mathrm{R}_{\mathrm{hs}, \mathrm{c}} \mathrm{Q}_{\mathrm{c}}+\mathrm{T}_{\mathrm{c}} \\
\mathrm{Q}_{\text {cooling load }}=\mathrm{UA}\left(\mathrm{T}_{\mathrm{o}}-\mathrm{T}_{\mathrm{i}}\right)
\end{gathered}
$$

In addition, $Q_{\text {cooling load }}$ can be obtained from eqns (3) and (4). By assuming $T_{c}$, not only $\mathrm{Q}_{\mathrm{c}}$ can be calculated from eqn (1) but cooling load from eqn (4). For the two-stage system, eqns (5)-(8) are used to find optimum ratio of current for each thermoelectric module and maximum $\mathrm{Q}_{\mathrm{c}}$. Using $\mathrm{Q}_{\mathrm{h}, 1}=\mathrm{Q}_{\mathrm{c}, 2}=\mathrm{Q}_{\mathrm{m}}, \mathrm{T}_{\mathrm{m}}$ is referred to eqn (9) from eqns (6)-(7). Eqn (9) is applied into eqn (5). Under the condition that $\mathrm{dQ}_{\mathrm{c}} / \mathrm{dI}=0$, the maximum $\mathrm{Q}_{\mathrm{c}}$ can be determined [5].

$$
\mathrm{Q}_{\mathrm{c}, 1}=\alpha_{1} \mathrm{I}_{1} \mathrm{~T}_{\mathrm{c}, 1}-\frac{1}{2} \mathrm{I}_{1}^{2} \mathrm{R}_{1}-\mathrm{K}_{1}\left(\mathrm{~T}_{\mathrm{m}}-\mathrm{T}_{\mathrm{c}, 1}\right)
$$




$$
\begin{gathered}
\mathrm{Q}_{\mathrm{h}, 1}=\alpha_{1} \mathrm{I}_{1} \mathrm{~T}_{\mathrm{h}, 1}+\frac{1}{2} \mathrm{I}_{1}{ }^{2} \mathrm{R}_{1}-\mathrm{K}_{1}\left(\mathrm{~T}_{\mathrm{m}}-\mathrm{T}_{\mathrm{c}, 1}\right) \\
\mathrm{Q}_{\mathrm{c}, 2}=\alpha_{2} \mathrm{I}_{2} \mathrm{~T}_{\mathrm{c}, 2}-\frac{1}{2} \mathrm{I}_{2}{ }^{2} \mathrm{R}_{2}-\mathrm{K}_{2}\left(\mathrm{~T}_{\mathrm{h}, 2}-\mathrm{T}_{\mathrm{m}}\right) \\
\mathrm{Q}_{\mathrm{h}, 2}=\alpha_{2} \mathrm{I}_{2} \mathrm{~T}_{\mathrm{h}, 2}+\frac{1}{2} \mathrm{I}_{2}{ }^{2} \mathrm{R}_{2}-\mathrm{K}_{2}\left(\mathrm{~T}_{\mathrm{h}, 2}-\mathrm{T}_{\mathrm{m}}\right) \\
\mathrm{T}_{\mathrm{m}}=\frac{\alpha_{1} \mathrm{I}_{1} \mathrm{~T}_{\mathrm{h}, 1}-\alpha_{2} \mathrm{I}_{2} \mathrm{~T}_{\mathrm{c}, 2}+\frac{1}{2} \mathrm{I}_{1}{ }^{2} \mathrm{R}_{1}+\frac{1}{2} \mathrm{I}_{2}{ }^{2} \mathrm{R}_{2}+\mathrm{K}_{1} \mathrm{~T}_{\mathrm{c}, 1}+\mathrm{K}_{2} \mathrm{~T}_{\mathrm{h}, 2}}{\mathrm{~K}_{1}+\mathrm{K}_{2}}
\end{gathered}
$$

\section{Results and discussion}

Figure 6 presents the cooling capacity of the single-stage thermoelectric system for different input currents. As the current was increased, $Q_{c}$ increased at first and decreased after the peak point. The peak point exists due to limitation of heat removal capacity of the heat sink on the hot side of the thermoelectric module. The maximum cooling capacity was $31.87 \mathrm{~W}$ at $6.4 \mathrm{~A}$.

Figure 7 indicates $\mathrm{Q}_{\mathrm{c}}$ of the two-stage systems against different input current ratios $\mathrm{I}_{2} / \mathrm{I}_{1}$. In this figure, the cuboid type two-stage system showed the lowest $\mathrm{Q}_{\mathrm{c}}$ since $\mathrm{Q}_{\mathrm{c}, 2}$ was too small to cover $\mathrm{Q}_{\mathrm{h}, 1}$ so $\mathrm{T}_{\mathrm{m}}$ of the cuboid type two-stage system was much higher than that of the pyramid. In other words, the capability of the bottom thermoelectric module must be bigger than that of the top module to maximize $\mathrm{Q}_{\mathrm{c}}$. This phenomenon happens because $\mathrm{Q}_{\mathrm{h}}$ is always bigger than $\mathrm{Q}_{\mathrm{c}}$ for commonly occurring designs of thermoelectric modules, which explains why the pyramid type two-stage system shows better results.

The pyramid type with heat transfer enhancement material showed better results than those of the pyramid type without any material. Generally, the thermoelectric module is made of material with a low conductance to prevent heat loss from both surfaces. For this reason, $\mathrm{Q}_{\mathrm{c}, 2}$ which is generated from exposed area of the bottom thermoelectric module cannot be transferred to the upper one effectively. However, if a material with high conductance is placed between two thermoelectric modules as shown in Fig. 2(d), most of the cooling capacity from the bottom thermoelectric module will be transferred to the top module. From these results, the maximum $\mathrm{Q}_{\mathrm{c}}$ of the pyramid type two-stage system with high conductance material showed $20.75 \%$ higher than that of the pyramid-type without an enhancement material.

Table 3 shows the maximum cooling capacity of each thermoelectric cooler. The pyramid type two-stage system showed about $10.5 \%$ higher cooling capacity than that of the single system. Also, the cuboid type two-stage system showed the worse result than any other systems including the single-stage system. 


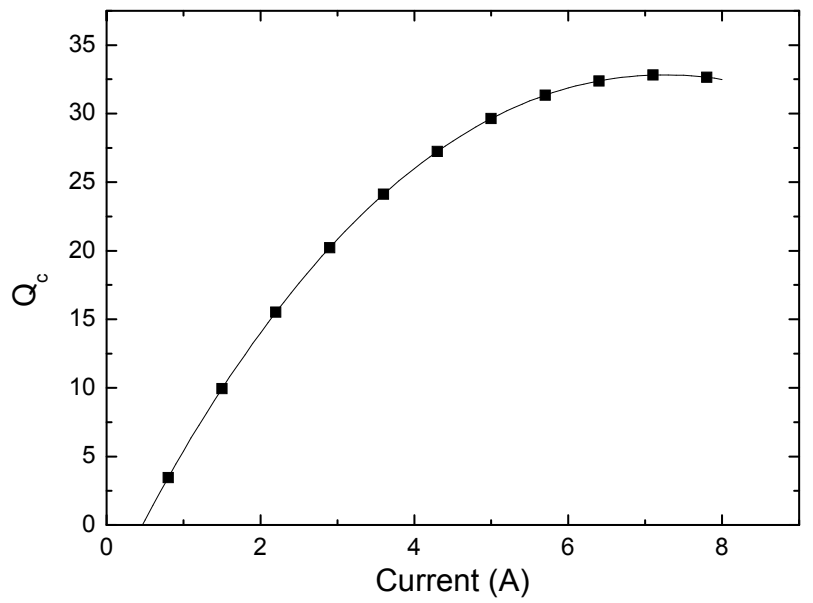

Figure 6: $\quad$ Variation of $\mathrm{Q}_{\mathrm{c}}$ with current for the single-stage system.

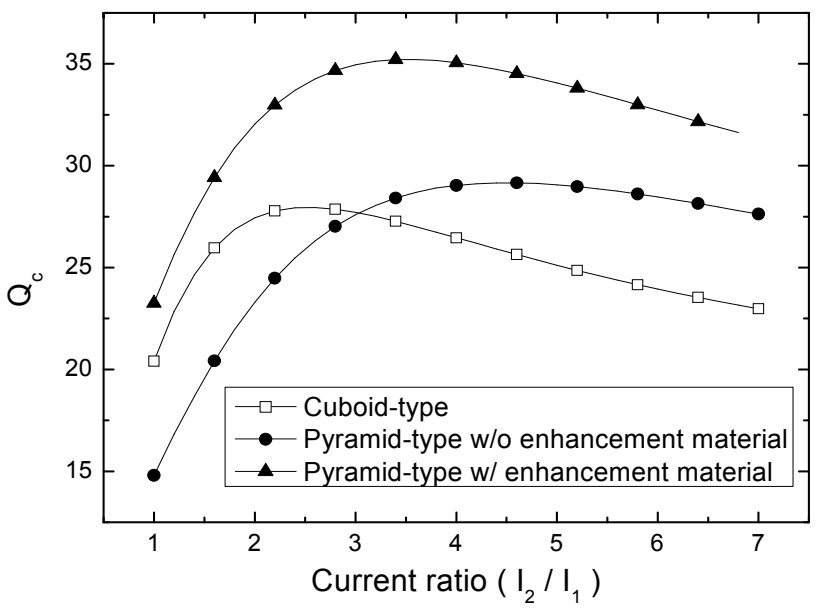

Figure 7: $\quad$ Variation of $\mathrm{Q}_{\mathrm{c}}$ with current ratio for the two-stage systems. 
Table 3: Maximum $\mathrm{Q}_{\mathrm{c}}$ for each system.

\begin{tabular}{|c|c|c|c|c|}
\hline & Single-stage & $\begin{array}{c}\text { Cuboid type } \\
\text { two-stage }\end{array}$ & $\begin{array}{c}\text { Pyramid type } \\
\text { two-stage } \\
\text { w/o material }\end{array}$ & $\begin{array}{c}\text { Pyramid type } \\
\text { two-stage w/ } \\
\text { material }\end{array}$ \\
\hline Max. $\mathrm{Q}_{\mathrm{c}}(\mathrm{W})$ & 31.87 & 27.95 & 29.16 & 35.21 \\
\hline $\begin{array}{c}\text { Ratio of } \\
\text { system to } \\
\text { single-stage }\end{array}$ & - & $87.70 \%$ & $91.50 \%$ & $110.48 \%$ \\
\hline
\end{tabular}

\section{Conclusion}

In this research, the theoretical design and analysis of thermoelectric cooler is presented. Several thermoelectric cooling systems were analyzed respectively. From the analytical study, the pyramid type two-stage system showed about $10.5 \%$ higher cooling capacity than that of the single-stage system. The bigger bottom thermoelectric module covered more $\mathrm{Q}_{\mathrm{h}}$ from the top thermoelectric module so it was more effective than any other system. In addition, it was helpful for inserting a high conductivity material between two thermoelectric modules to optimize the pyramid type two-stage thermoelectric system. The maximum cooling capacity of the pyramid-type material with high conductance material was shown to be $20.75 \%$ higher than that of an ordinary pyramid-type system. The high conductance material helped in transferring heat away from the contact area.

\section{References}

[1] Jincan Chen, Yinghui Zhou, Hongjie Wang \& Jin T. Wang, Comparison of the optimal performance of single- and two-stage thermoelectric refrigeration systems, Applied Energy, 73, pp. 285-298, 2002.

[2] Jianlin $\mathrm{Yu} \&$ Beiming Wang, Enhancing the maximum coefficient of performance of thermoelectric cooling modules using internally cascaded thermoelectric couples, International Journal of Refrigeration, 32, pp. 32-39, 2009.

[3] B.J. Huang, C.J. Chin \& C.L. Duang, A design method of thermoelectric cooler, International Journal of Refrigeration, 23, pp. 208-218, 2000.

[4] Lingen Chen, Jun Li, Fengrui Sun \& Chih Wu, Performance optimization for a two-stage thermoelectric heat-pump with internal and external irreversibilities, Applied Energy, 85, pp. 641-649, 2008.

[5] X.C. Xuan, K.C. Ng, C. Yap \& H.T. Chua, Optimization of two-stage thermoelectric coolers with two design configurations, Energy Conversion and Management, 43, pp. 2041-2052, 2002. 